\title{
Defect Clustering in Simple and Complex Oxides
}

\author{
Progress Report \\ PERIOD $6 / 1 / 192-5 / 3 / 193$
}

T. O. Mason

\section{Northwestern University \\ Evanston, IL 60208}

\section{October 1992 \\ DISCLAIMER}

This report was prepared as an account of work sponsored by an agency of the United States Government. Neither the United States Government nor any agency thereof, nor any of their employees, makes any warranty, express or implied, or assumes any legal liability or responsibility for the accuracy, completeness, or usefulness of any information, apparatus, product, or process disclosed, or represents that its use would not infringe privately owned rights. Reference herein to any specific commercial product, process, or service by trade name, trademark, manufacturer, or otherwise does not necessarily constitute or imply its endorsement, recommendation, or favoring by the United States Government or any igency thereof. The views and opinions of authors expressed herein do not necessarily state or reflect those of the United States Government or any agency thereof.

\section{Prepared for}

THE U.S. DEPARTMENT OF ENERGY AGREEMENT NO. DE-FG02-84ER45097 
Title: Defect Clustering in Simple and Complex Oxides

Principal Investigators: J, B. Cohen, D. E. Ellis, and T. O. Mason

Date: October 16, 1992

\author{
Progress Report
}

\title{
A. Technical Achievements
}

To facilitate in situ neutron diffraction studies of oxides, an environmental cell capable of $1673 \mathrm{~K}$ under controlled atmospheres (1 atm total pressure) was constructed and successfully employed [1]. In addition, we continue to perfect our codes for correction and analysis of in situ single crystal diffuse $x$-ray scattering from oxides [2].

We have pioneered the development of a high oxygen pressure cell for simultaneous high oxygen pressure (1-35 atm) and high temperature transport studies. For example, using such a cell we successfully achieved $\delta=0.044$ in $\mathrm{Co}_{1-} \mathrm{O}$ at $32 \mathrm{~atm}$ oxygen and $1200^{\circ} \mathrm{C}$ [3]. With the advent of superconductivity in cuprates, which often require high oxygen pressure treatments, similar cells are now commercially available. We are currently modifying a Morris Research furnace for electrical property measurements to $200 \mathrm{~atm}$.

On the theoretical front, we continue to develop our embedded cluster approach within the local density framework to model the energetics of defect structures in oxides [4]. We are now able to predict local lattice relaxation and geometries associated with defects. In addition, the details of electronic structure can be predicted and compared with experiment, e.g. X-ray near edge structure.

The strength and collaborative nature of our interdisciplinary program can best be illustrated by discussing our progress in simple and complex oxides (below).

\section{Simple Oxides}

In surveying $\mathrm{m}: \mathrm{n}$ vacancy:interstitial clusters in $\mathrm{Fe}_{1-\mathrm{x}} \mathrm{O}$ such as the $1: 1,2: 1,4: 1,6: 2$, $7: 2$, and 13:4, our theoretical team showed the 7:2 cluster to be the most stable, followed closely by the $4: 1$ [5]. In situ powder diffraction patterns from $\mathrm{Fe}_{1-x} \mathrm{O}$ were taken in a specially designed environmental cell at the Intense Pulsed Neutron Source (IPNS) at ANL [2]. Rietveld analysis of the numerous diffraction peaks permitted the interstitial population to be quite precisely established, and therefore the vacancy-to-interstitial ratio to be constrained. A distinction was therefore possible between proposed point defect clusters. The 4:1 prevails at high temperatures or at Fe-rich compositions, giving way to $7: 2$ and 10:3 clusters as the temperature or Fe content decreases. A small polaron conduction model, based upon the clusters detected, yielded excellent agreement with the measured electrical properties.

In $\mathrm{Mn}_{1-x} \mathrm{O}$, our theoretical effort predicted the 2:1 cluster to be the most stable among those surveyed, followed closely by the 6:2 (see above [5]). It should be stressed that this prediction was made prior to diffraction studies or electrical property modeling. In situ single crystal X-ray diffuse scattering from $\mathrm{Mn}_{1-x} \mathrm{O}(0<\mathrm{x} \leq 0.056)$ at $1573 \mathrm{~K}$ [1] showed no superstructure peaks or diffuse maxima in reciprocal space where such features occur in $\mathrm{Fe}_{1-\mathrm{x}} \mathrm{O}$. For the first time, however, neutron powder diffraction patterns analyzed by Rietveld technique showed a definitive interstitial population of 2(1) percent at $x=.09$ in $\mathrm{Mn}_{1-x} \mathrm{O}$ at $1323 \mathrm{~K}$ [1]. The 
vacancy-to-interstitial ratio of 5.5 is indicative of a mixture of small cation vacancy clusters and unassociated cation vacancies. Kröger-Vink modeling of the available nonstoichiometry data and our electrical property data $(1673 \mathrm{~K})$ could be achieved with a combination of isolated cation vacancies, quadruply-charged (6:2)" "' clusters, and a neutral $(m: n)^{x}$ species with $m-n=1$, e.g. $(1: 0),(2: 1)$, etc. The ultimate interstitial content at $x=.09$ from this modeling is in good agreement with the Rietveld result. All three efforts--theoretical, structural, electrical--point to the existence of small vacancy:interstitial clusters in $\mathrm{Mn}_{1-\mathrm{x}} \mathrm{O}$.

Despite considerable progress, the situation in $\mathrm{Co}_{1-x} \mathrm{O}$ remains unresolved at this time. Based upon an entire suite of physical property measurements--nonstoichiometry, cation tracer diffusion, electrical property measurements--in a high oxygen pressure cell [3] over the previously uninvestigated range of $0.003 \leq x \leq 0.044$, a new defect model was proposed [6].

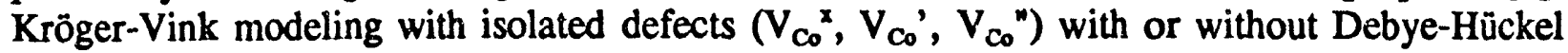
interactions could not fit the data. Neither could a model without Debye-Hückel interactions but invoking clusters in addition to isolated vacancies provide a good fit. However, a model incorporating triply-charged (4:1)" clusters with Debye-Hückel interactions fits all the expermental data quite well. At present there is no corroborating evidence for clusters in $\mathrm{Co}_{1-x} \mathrm{O}$. Theoretical calculations suggest the $(2: 1)$ cluster to be the most stable associate in $\mathrm{Co}_{1-x} \mathrm{O}$ [5]; diffraction studies at these high pressures have yet to be attempted (see below).

\section{Complex Oxides}

We have made considerable progress on the $n=1$ phases of the $R_{2} A E_{n-1} C u_{n} O_{2 n+2}$ series ( $R E=$ rare earth, $A E=$ alkaline earth). Our in situ electrical measurements of $\mathrm{La}_{2-x} \mathrm{Ba}_{x} \mathrm{CuO}_{4 \pm \delta}$ were reported some tirne ago [7]. A schematic point defect model and Brouwer diagram were subsequently outlined in [8]. The model involves $O_{i}$ " at low dopant concentrations, the expected $\mathrm{p}=\left[\mathrm{Ba}_{\mathrm{L}}{ }^{\prime}\right]$ regime at intermediate concentrations, and $\mathrm{V}_{\mathrm{O}}$ " or associates, e.g. $\left(\mathrm{V}_{\mathrm{O}}{ }^{\prime} \mathrm{Ba}_{\mathrm{LA}}{ }^{\prime}\right) \cdot$ at high concentrations. A similar model has also been proposed by Maier and Tuller [9]. We are currently testing this model against nonstoichiometry data (see proposed research); diffraction experiments will be conducted in the future (see below).

We also recently reported high temperature electrical property data for the $\mathrm{Nd}_{2-x} \mathrm{Ce}_{\mathrm{x}} \mathrm{CuO}_{4 \pm \delta}$ solid solution [10]. The defect behavior appears to be a mirror image of that in $\mathrm{La}_{2-x} \mathrm{Ba}_{x} \mathrm{CuO}_{4 \pm 8}$. Oxygen vacancies predominate at low doping levels, giving way to the $\mathbf{n}=\left[\mathrm{Ce}_{\mathrm{Nd}}\right]$ regime at intermediate levels, and oxygen interstitials (or possibly associates) at high doping levels. A schematic point defect model and Brouwer diagram have been proposed [8].

There are important practical ramifications of the point defect structure in $\mathrm{Nd}_{2-x} \mathrm{Ce}_{x} \mathrm{CuO}_{4 \pm d}$ for high $\mathrm{T}_{\mathrm{c}}$ superconductivity. Jorgensen and coworkers have suggested the co-existence of two sub-phases in this solid solution, based upon Rietveld analysis of neutron diffraction patterns [11]. To probe local atomic arrangements in this system, diffuse X-ray scattering experiments have been initiated at the National Synchrotron Light Source (NSLS) located at Brookhaven National Lab (BNL). Some 3000 data points were sampled in a volume of reciprocal space at two energies near the $\mathrm{Cu}-\mathrm{K}$ absorption edge. By taking the difference, all pairs except those involving $\mathrm{Cu}$ were eliminated. The first aim of this work was to determine distortions in the $\mathrm{CuO}_{2}$ plane. This a "tour de force" experiment, in that no one has yet attempted a quantitative analysis of diffuse scattering from a tetragonal ceramic crystal with so large a number of atoms in the unit cell. It is too early to say more than that there are unusual features in the diffuse intensity maps. Assuming this analysis proves fruitful, the $\mathrm{Nd}$ and $\mathrm{Ce}$ edges will be probed for local order about these sites. 
In parallel with the electrical and structural efforts, the electronic structure of $\mathrm{La}_{2} \mathrm{CuO}_{4}$ based (and other) cuprates has been explored via the embedded cluster/local density approach [12-14]. The effective valence of $\mathrm{Cu}$ was investigated, in conjunction with high quality X-ray absorption near edge studies. A simple linear relation between calculated $\mathrm{Cu}$ net charge and $\mathrm{X}$ ray "characteristic energy" was found, which permits easy identification of $\mathrm{Cu}$ valence state. The absence of $\mathrm{Cu}^{3+}$ signal either in theory or in experiment helps to narrow the range of plausible superconductivity mechanisms.

In support of the collaborative effort with D. J. Lam and coworkers at ANL, the electronic properties of pure and transition metal-doped $\alpha-\mathrm{Al}_{2} \mathrm{O}_{3}$ (sapphire) were calculated. The convergence rate of one-electron and energetic (total energy) properties vs. cluster size and geometry was investigated in bulk material [15]. Building upon this work, the electronic structure and energetics of the experimentally important $(0001)$ and $(0112)$ surfaces were studied [16]. Using the idea of neutral "surface building blocks," a way was found to rationalize and predict the relative stability of possible cleavage planes. These results are proving useful for understanding which low energy surfaces can be formed to stimulate epitaxial growth of oxides on sapphire substrates. Attempts to predict the local minimum energy geometry and the related lattice relaxation mechanisms are underway.

\section{References}

1. M. J. Radler, J. B. Cohen, G. P. Sykora, and T. Mason, "The Defect Structures of $\mathrm{Mn}_{1-x} \mathrm{O}$," J. Phys. Chem. Solids, 53 [1] 141-54 (1992).

2. M. Radler, J. B. Cohen, and J. Faber, Jr., "Point Defect Clusters in Wüstite," J. Phys. Chem. Solids, 51 [3] 217-28 (1990).

3. K. P. Constant, T. O. Mason, S. J. Rothman, and J. L. Routbort, "Non-Stoichiometry, Electrical Properties, and Cation Diffusion in Highly Non-Stoichiometric $\mathrm{Co}_{1-x} \mathrm{O}-\mathrm{-I}$. Experimen'al," J. Phys. Chem. Solids, 55 [3] 405-11 (1992).

4. D. E. Ellis, J. Guo, and D. J. Lam, "Embedded Cluster Model of Oxide Ceramics," J. Am. Ceram. Soc., 733231 (1990).

5. P. K. Khowash and D. E. Ellis, "Defect Structure in Transition Metal Monoxides," Phys. Rev. B, 39, 1908-13 (1989).

6. K. P. Constant, T. O. Mason, S. J. Rothman, and J. L. Routbort, "Non-Stoichiometry, Electrical Properties, and Cation Diffusion in Highly Non-Stoichiometric $\mathrm{Co}_{1-\mathrm{x}} \mathrm{O}-\mathrm{-I}$. Modeling the Defect Structure," J. Phys. Chem. Solids, 55 [3] 413-18 (1992).

7. M. -Y. Su, C. E. Elsbernd, and T. O. Mason, "Jonker 'Pear' Analysis of Oxide Superconductors," J. Am. Ceram. Soc., 73 [2] 415-19 (1990).

8. T. O. Mason, "Defect Chemistry of High $T_{c}$ Superconducting Cuprates," in Electronic Ceramic Materials, J. Nowotny, Ed., Trans Tech Publ., Zürich (1992) pp. 503-36.

9. J. Maier and G. Pfundtner, "Defect Chemistry of the High $T_{c}$ Superconductors," Adv. Mater., 3 [6] 292-97 (1991); see also H. L. Tuller, "Oxygen Ion Transport and Disorder in Cuprates, " in Ceram. Trans. Vol 18, K. M. Nair, U. Balachandran, Y. -M. Chiang, and A. S. Bhalla, Eds., American Ceramic Society, Westerville, OH (1991) pp. 107-20.

10. C. N. Pieczulewski, M. Atristain, M. -Y. Su, and T. O. Mason, "Phase Equilibria, Defect Chemistry, and High Temperature Electrical Properties in the System Nd-Ce-Cu-O, " in Ceram. Trans. Vol. 13, K. M. Nair and E. A Giess, Eds., American Ceramic Society, Westerville, $\mathrm{OH}$ (1990) pp. 99-114. 
11. J. D. Jorgensen and G. D. Hinks, "Multiphase Behavior and Superconducting Composition - in $\mathrm{Nd}_{2-\mathrm{C}} \mathrm{Ce}_{\mathrm{x}} \mathrm{CuO}_{4-8}$, " Physica B, 165-6, 1509-10 (1990); also see Lightfoot, Richards, Dabrowski, "Phase Separation in $\mathrm{Nd}_{2-x} \mathrm{Ce}_{x} \mathrm{CuO}_{4}$," Physica C. 168, 627-36 (1990).

12. J. Guo, D. E. Ellis, G. L. Goodman, E. E. Alp, L. Soderholm, and G. K. Shenoy, "Theoretical Calculations of X-ray Absorption Spectra of Copper in $\mathrm{La}_{2} \mathrm{CuO}_{4}$ and Related Compounds," Phys. Rev. B, 41, 82 (1990).

13. J. Guo, D. E. Ellis, E. E. Alp, and G. L. Goodman, "Polarized Copper K-Edge X-ray Absorption Spectra of $\mathrm{YBa}_{2} \mathrm{Cu}_{3} \mathrm{O}_{7 . y}$ and Related Compounds," Phys. Rev. B, 42, 251 (1990).

14. D. E. Ellis, J. Guo, and D. J. Lam, "Embedded Cluster Models of Ceramic Electronic Properties," Rev. Solid State Sci., 5282 (1991); also in "Quantum Mechanical Cluster Calculations in Solid State Studies, " R. W. Grimes, C. R. A. Catlow, and A. L. Shluger, Eds., World Scientific, Singapore (1992) p227.

15. J. Guo, D. E. Ellis, and D. J. Lam, "First Principles Calculatiuns of Electronic Structure of Sapphire, Bulk Properties," Phys. Rev. B, 45, 3240 (1992).

16. J. Guo, D. E. Ellis, and D. J. Lam, "Electronic Structure and Energetics of Sapphire (0001) and (0112) Surfaces," Phys. Rev. B, 45, 13647 (1992). 


\section{Appendix A}

DOE Publications 1990-1992: J. B. Cohen, D. E. Ellis, T. O. Mason

"Point Defect Clusters in Wüstite", M. Radler, J. B. Cohen and J. Faber, Jr., J. Phys. Chem. Solids, 51,\#3,217-228, 1990.

"Thermal Diffuse Scattering in Neutron Time-of-Flight Powder Patterns", M. Radler, Mat.Res.Soc.Symp.Proc., 166, 67-73 (1990).

"Point Defect Clusters in Transition Metal Monoxides", J. B. Cohen, Morris E. Fine Symposium, Eds. , P.K. Liaw, J. R. Weertman, H.L. Marcus, J. S. Santer, TMS Fall Meeting, pgs 3-6, October (1990).

"Diffraction Studies of Point Defects in Transition Metal Monoxides", Ceramic Transactions, Vol. 24, T. O. Mason, J. L. Routbort, M. J. Radler and J. B. Cohen, Eds., American Ceramic Society, 1992, pp 41-48.

"The Defect Structure of $\mathrm{Mn}_{1-\mathrm{x}} \mathrm{O}$ ", M. J. Radler, J. B. Cohen, G. P. Sykora, T. O. Mason, D. E. Ellis, and J. Faber Jr., J. Phys. Chem Solids,53 [1], 141-154 (1992).

"Theoretical Calculations on X-ray Absorption Spectra of Copper in $\mathrm{La}_{2} \mathrm{CuO}_{4}$ and related Compounds, J. Guo, D. E. Ellis, G. L. Goodman, E. E. Alp, L. Soderholm and G. K. Shenoy, Phys. Rev.,B42, 82 (1990).

"Polarized Copper K-edge X-ray Absorption Spectra of $\mathrm{YBa}_{2} \mathrm{Cu}_{3} \mathrm{O}_{7-\mathrm{y}}$ and Related Compounds, J. Guo, D. E. Ellis, E. E. Alp and G. L. Goodman, Phys. Rev.,B42, 251 (1900).

"Embedded Cluster Model of Oxide Ceramics", D. E. Ellis, J. Guo and D. J. Lam, J. Ain.Cer.Soc. ,73, 3231 (1990).

"Embedded Cluster Models of Ceramic Electronic Properties", D. E. Ellis, J. Guo and D. J. Lam, Revs. Solid State Sci., 5, 282 (1991); also in "Quantam Mechanical Cluster Calculations in Solid State Studies", eds. R. W. Grimes, C. R. A. Catlow, and A. L. Shluger, (World Scientific, Singapore, 1992) p. 227.

"First Principles Calculations of Electronic Structure of Sapphire, Bulk Properties", J. Guo, D. E. Ellis and D. J. Lam, Phys. Rev., B45, 3240 (1992). 


\section{- Appendix A}

NOE Publications: Cohen, Ellis, Mason cont'd

"Electronic Structure and Energetics of Sapphire (0001) and (0112) Surfaces", J. Guo, D. E. Ellis and D. J. Lam, Phys. Rev., B45, 13647 (1992).

"Hyperfine Interactions in Iron Substituted High-T $\mathrm{T}_{\mathrm{c}}$ Superconductors, D. E. Ellis, E. BaggioSaitovitch and D. J. Lam, Physica C, in press.

"Jonker 'Pear' Analysis of Oxide Superconductors", M. -Y. S. E. Elsbernd, and T. O. Mason, J. Am. Cer. Soc. $\underline{73}$ [2] 415-19 (1990).

"High-Temperature Defect Structure of Lanthanum Cupate", M. -Y. Su, E. A. Cooper, C. E. Elsbernd, and T. O. Mason, J. Am. Cer. Soc., 73 [11] 3453-56 (1990).

"Phase Equilibria Defect Chemistry, and High Temperature Electrical Properties in the System Nd-Ce-Cu-O", C. N. Pieczulewski, M. Atristain, M. -Y. Su, and T. O. Mason, Proc. Intl. Symp., Ceramic Transations: Ceramic Superconductors, Vol. 13, K. M. Nair and E. A. Giess, Eds., American Ceramic Society, Westerville, OH (1990) pp. 99-114.

"Defect Chemistry of High $\mathrm{T}_{\mathrm{c}}$ Superconducting Cuprates", T. O. Mason in Ceramic Materials for Electronics, J. Nowotny, Ed., Trans Tech Publishing, 1991, pp. 503-36.

"Solid Solution and Defect Behavior in High $T_{c}$ Oxides", B. -S. Hong and T. O. Mason, in Ceramic Transactions, Vol. 18, Edited by K. M. Nair, U. Balanchandran, Y. -M. Chiang, and A. S. Bhalla, American Ceramic Society, Westerville OH (1991) pp 95-106.

"Nonstoichiometry ELectrical Properties, and Cation Diffusion in Highly Nonstoichiometric $\mathrm{Co}_{1 \text { - }}$ ${ }_{x}$ O.I. Experimental ${ }^{n}$, K. L. Persels, T. O. Mason, S. J. Rothman, and J. L. Routbort, J. Phys. Chem. Solids, 55 [3] 405-11 (1992).

"Nonstoichiometry Electrical Properties, and Cation Diffusion in Highly Nonstoichiometric $\mathrm{Co}_{1}$. xO.II. Modelling the Defect Structure", K. L. Persels, T. O. Mason, and J. L. Routbort, J. Phys. Chem. Solids, 55 [3] 413-18 (1992).

"Comment on 'On the Use of Oxides for Thermoelectrical Refrigration"", T. O. Mason, Mat.Sci. \& Eng. B. 10, 257-60 (1991).

"Defect Structure Studies in Highly Nonstoichiometric $\mathrm{Co}_{1-\mathrm{x}} \mathrm{O}$, K. L. Persels, T. O. Mason, and J. L. Routbort, Eds. American Ceramic Society, Westerville, OH (1991) pp 31-40. 

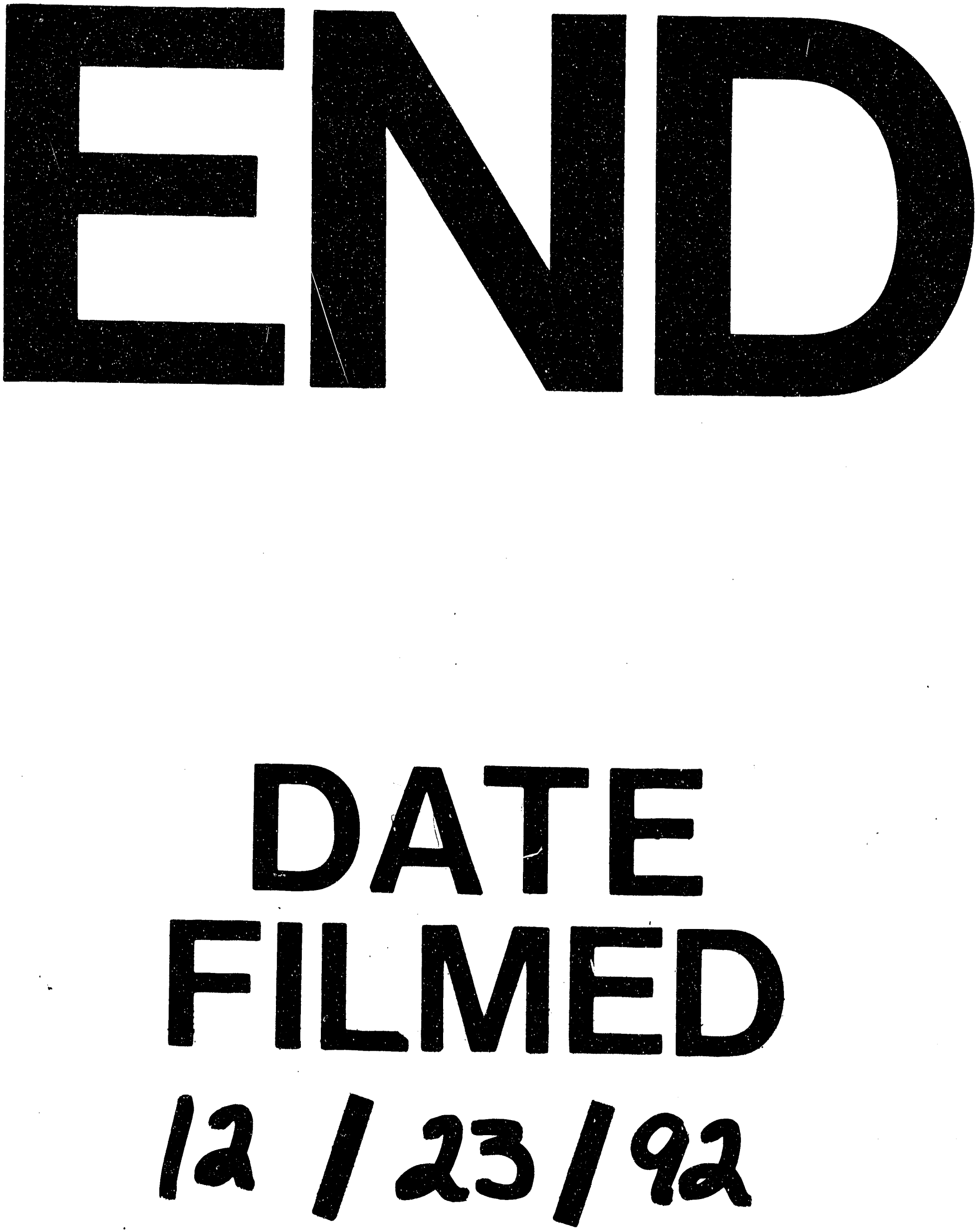
